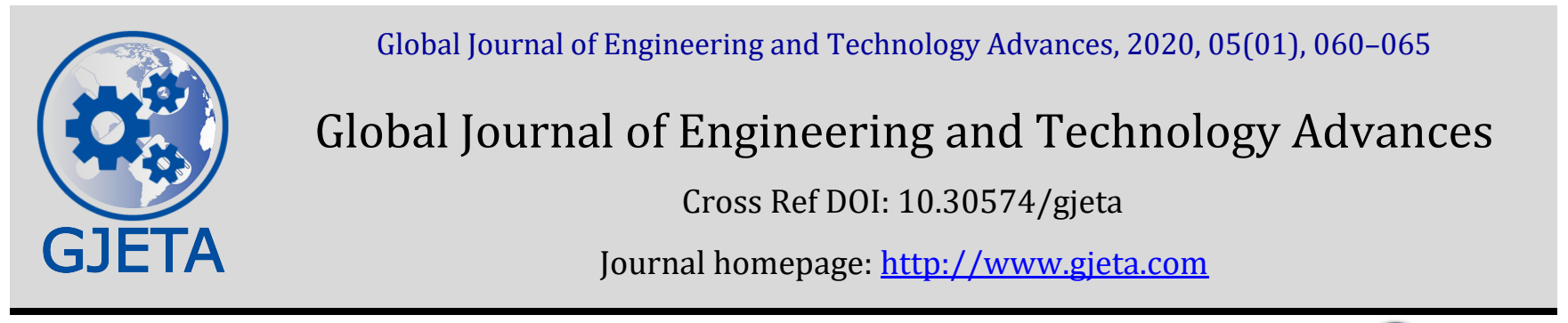

(RESEARCH ARTICLE)

\title{
Preliminary design of a radio-controlled micro aircraft for student competition
}

\author{
Ali Dinc*, Yousef Gharbia, Mariam AlShammari, Aliah AlRasheedi, Shahad AlQallaf, Mayar AlIbrahim and \\ Shahad AlObaid
}

College of Engineering and Technology, American University of the Middle East, Kuwait.

Publication history: Received on 20 September 2020; revised on 27 September 2020; accepted on 29 September 2020

Article DOI: https://doi.org/10.30574/gjeta.2020.5.1.0076

\begin{abstract}
This work presents a preliminary design study of a radio-controlled micro aircraft. The aircraft is designed with the aim to compete in the SAE Aero Design Student Competition. Different designs were performed by different groups of students following the rules given in the SAE 2017 competition document. Such rules include the criteria of having the entire aircraft fit in a specific dimensional cylindrical box in unassembled condition, achieving the highest flight score and carrying the highest possible payload with minimum airframe weight, etc. In this scope, the concept generations of multiple designs for the micro aircraft with appropriate dimensions were done. In addition, basic paper prototypes of the designs which were helpful to visualize the aircraft were constructed. 3D CAD models of designs and 2D drawings for dimensional description were prepared. No prototypes were manufactured due to the Covid-19 situation.
\end{abstract}

Keywords: Aircraft design; Radio controlled aircraft; Micro aircraft; Student competition.

\section{Introduction}

The Society of Automotive Engineers' (SAE) Aero Design competition is a competition held every year to prepare engineering students for a real-life engineering challenge [1]. The competition is divided into three different classes: regular, advanced, and micro. In this study, "micro" class has been selected. A design and development process was needed for operational aircraft with the object of maximizing the aircraft's payload while minimizing the aircraft's empty weight. The final score is the summation of sub-scores such as technical design report, presentation, flight score and penalties.

The aim of the project is to design a micro radio-controlled aircraft that will compete in SAE micro aircraft competition. The aircraft is designed to carry a certain payload as specified by rules of the competition.

The aircraft design is a typical process of engineering design. The design of aircraft is depending on several factors like customer requirements, protocols for safety, economic and physical restrictions, and others. For civil aircraft, the design must be certified by national airworthiness authorities to enter into service. The design of aircraft is an agreement among several contending factors and restrictions. It is a competition among present designs and for market demand to create superior aircraft.

There are several factors that set restrictions on the process of aircraft design such as budget restrictions, market demands, conflicts and environmental factors. The competition between companies makes them improve the aircraft design to be more efficient and better performing which often requires implementation and insertion of novel and state of the art technologies.

\footnotetext{
*Corresponding author: Ali Dinc, Phone:+965 22251400; e-mail: Ali.Dinc@aum.edu.kw College of Engineering and Technology, American University of the Middle East, Kuwait. 


\section{Material and methods}

Preliminary design of an aircraft starts with initial size and weight estimates. A simplified algorithm for aircraft size and weight calculation is presented here [2-11]. Some assumptions on parameters (weight of payload, payload fraction, wing loading, aspect ratio) need to be made for start. Those assumptions can be made using competitor study analysis or benchmarking study [12-14]. Below is an example calculation using sizing algorithm:

- $\quad \mathrm{W}_{\mathrm{pl}}$ : weight of payload $=1.206 \mathrm{~kg}$ (assumed)

- $\quad \mathrm{F}_{\mathrm{pl}}$ : payload fraction $=0.773$ (assumed)

- WL : wing loading = 6.64 (assumed)

- $\quad$ AR : Aspect Ratio = 5 (assumed)

$\mathrm{F}_{\mathrm{pl}}=\mathrm{W}_{\mathrm{pl}} / \mathrm{W}_{\mathrm{o}}$

the total weight of aircraft $\left(\mathrm{W}_{\mathrm{o}}\right)$ is:

$\mathrm{W}_{\mathrm{o}}=\mathrm{W}_{\mathrm{pl}} / \mathrm{F}_{\mathrm{pl}}=1.206 / 0.773=1.56 \mathrm{~kg}$

The wing loading $=\mathrm{WL}=\mathrm{W}_{\mathrm{o}} / \mathrm{S}=$ (total weight of aircraft $) /($ wing area $)$

the wing area $=\mathrm{S}=\mathrm{W}_{\mathrm{o}} / \mathrm{WL}=1.56 / 6.64=0.234 \mathrm{~m}^{\wedge} 2$

$\mathrm{S}=\mathrm{b} * \mathrm{c}$

where S: wing area ; b = wingspan or wing length; $c$ : chord length or wing width

$\mathrm{AR}=$ Aspect Ratio $=\mathrm{b} / \mathrm{c}$

$\mathrm{c}=\mathrm{S} / \mathrm{b}$

$\mathrm{b}=\mathrm{AR}^{*} \mathrm{c}$

$\mathrm{b}=\mathrm{AR}^{*}(\mathrm{~S} / \mathrm{b})$

$\mathrm{b}^{2}=\mathrm{AR}^{*} \mathrm{~S}$

$\mathrm{b}=\sqrt{ }\left(\mathrm{AR}^{*} \mathrm{~S}\right)=\sqrt{ }\left(5^{*} 0.234\right)=1.0763 \mathrm{~m}$ wing length $(\mathrm{span})$ and $\mathrm{c}=\mathrm{S} / \mathrm{b}=0.215 \mathrm{~m}$ wing width (chord)

Tail calculation:

Horizontal tail: Assuming horizontal tail area is $16.5 \%$ of main wing area (from benchmarking data):

$\mathrm{S}_{\mathrm{HT}}=\mathrm{S}_{\text {wing }}{ }^{*} 0.165=0.234 * 0.165=0.038 \mathrm{~m}^{2}$

Assume AR for horizontal tail=2.8

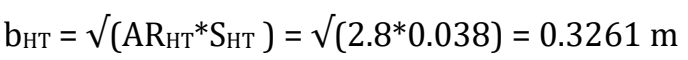

$\mathrm{C}_{\mathrm{HT}}=\mathrm{S}_{\mathrm{HT}} / \mathrm{b}_{\mathrm{HT}}=0.1165 \mathrm{~m}$

Vertical tail: Assuming vertical tail area is $6.9 \%$ of main wing area (from benchmarking data):

$\mathrm{S}_{\mathrm{VT}}=\mathrm{S}_{\text {wing }} * 0.069=0.2317 * 0.069=0.0148 \mathrm{~m}^{2}$

Assuming AR for vertical tail = bvт $/ \mathrm{cvv}_{\mathrm{T}}=\mathbf{= 1 0 1}$ (from benchmarking data):

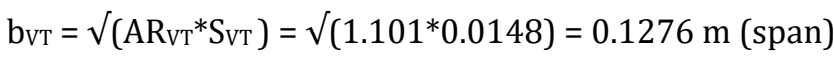


$\mathrm{C}_{\mathrm{VT}}=\mathrm{S}_{\mathrm{VT}} / \mathrm{b}_{\mathrm{VT}}=0.1159 \mathrm{~m}$ (chord)

Flight score (FS):

$\mathrm{FS}=\left(70-\mathrm{L}_{\mathrm{ac}}\right) *(2 * \mathrm{PF})$

$=(70-13.78) *(2 \times 0.773)=86.9$

Where FS is the flight score, $\mathrm{Lac}_{\mathrm{ac}}$ is the length (in inches) of aircraft container and PF is the payload fraction ( $\left.\mathrm{F}_{\mathrm{pl}}\right)$.

\begin{tabular}{l}
\hline Task \\
\hline Work Plan \\
Current State \\
Customer Requirements \\
Design Specification \\
Benchmarking \\
House of quality \\
Cost Analysis \\
Realistic External Constrair \\
Standards \& Codes \\
\hline Conceptual Design \\
\hline Design Selection Criteria \\
Generate alternative solutior \\
The impact of engeneering 1 \\
Size and weight calculation \\
Engeneering standard \\
Select best solution for the \\
Advantages 8 Disadvantages \\
Design objectives \\
Conceptual Design generati \\
Calculation design 1 \\
Calculation design 2 \\
Customer Requirements ch \\
External constrain checklist \\
Design and Construction \\
\hline Sketch prototype \\
30 Drawing \\
20 Drawing \\
\hline \hline
\end{tabular}

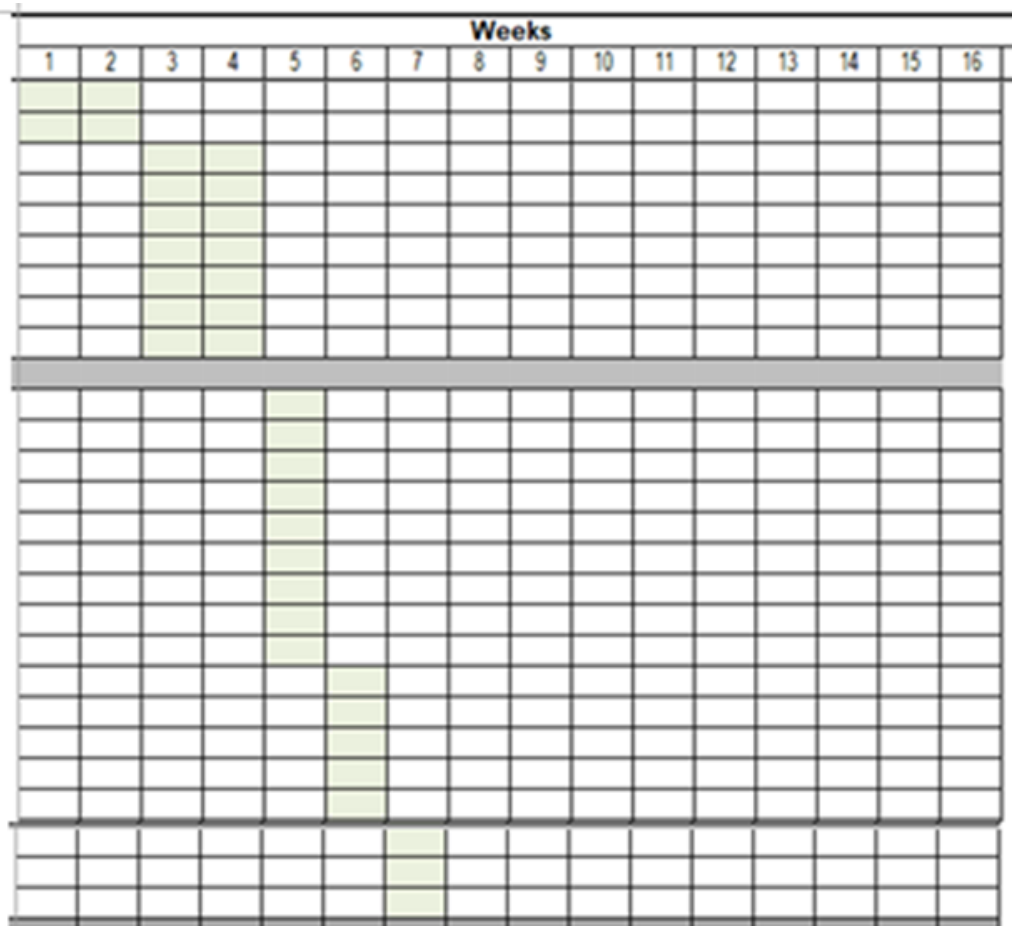

Figure 1 Project plan

For the planning of project activities, a Gantt chart type of plan was prepared as given in Figure 1. The activities were coordinated weekly based on this plan.

\section{Results and discussion}

After the size and weight calculations, firstly 2D hand sketches were drawn for each of the alternative designs as depicted in Figure 2. Then paper models (rough prototypes) were prepared to visualize the designs and also to make a trial of fitting the parts into the aircraft container as specified by the competition rules as shown in Figure 3.
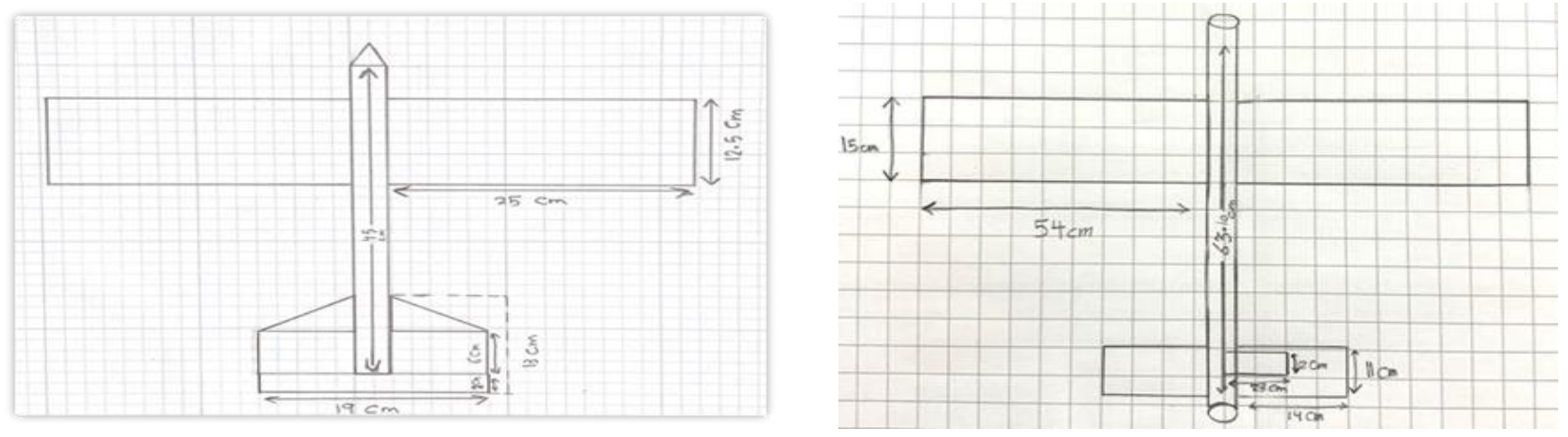

Figure 2 Hand sketches of alternative designs 

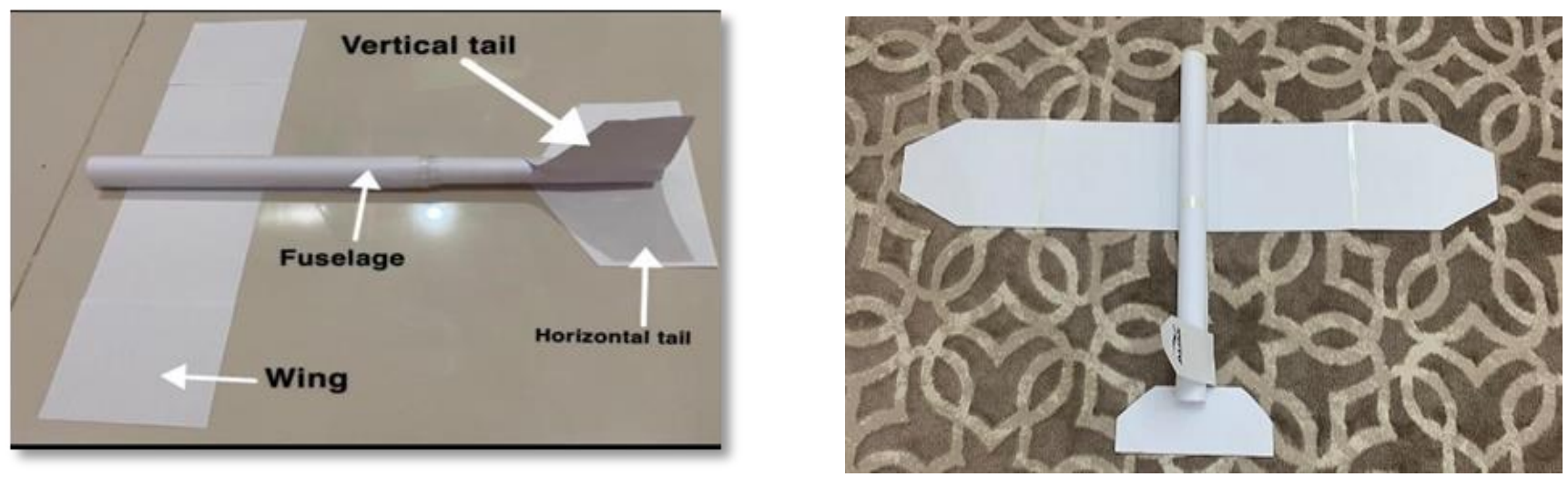

Figure 3 Paper models of alternative designs

After producing paper models and initial checks on dimensions with aircraft container, 3D CAD models were prepared for each alternative design (Figure 4-5).
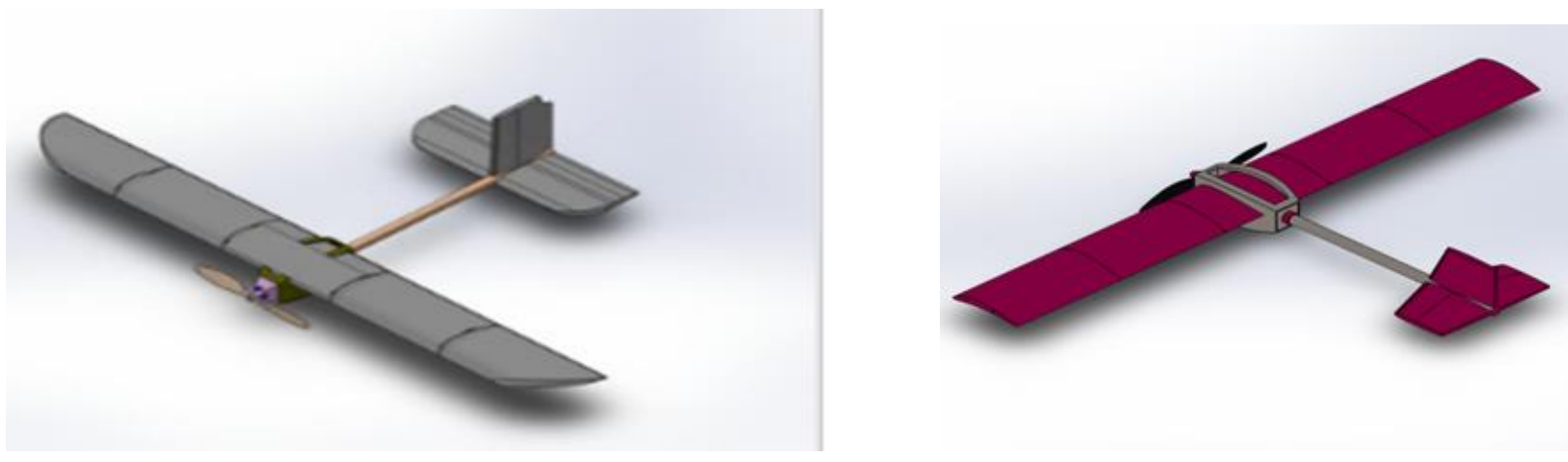

Figure $4 \mathrm{CAD}$ models of alternative designs
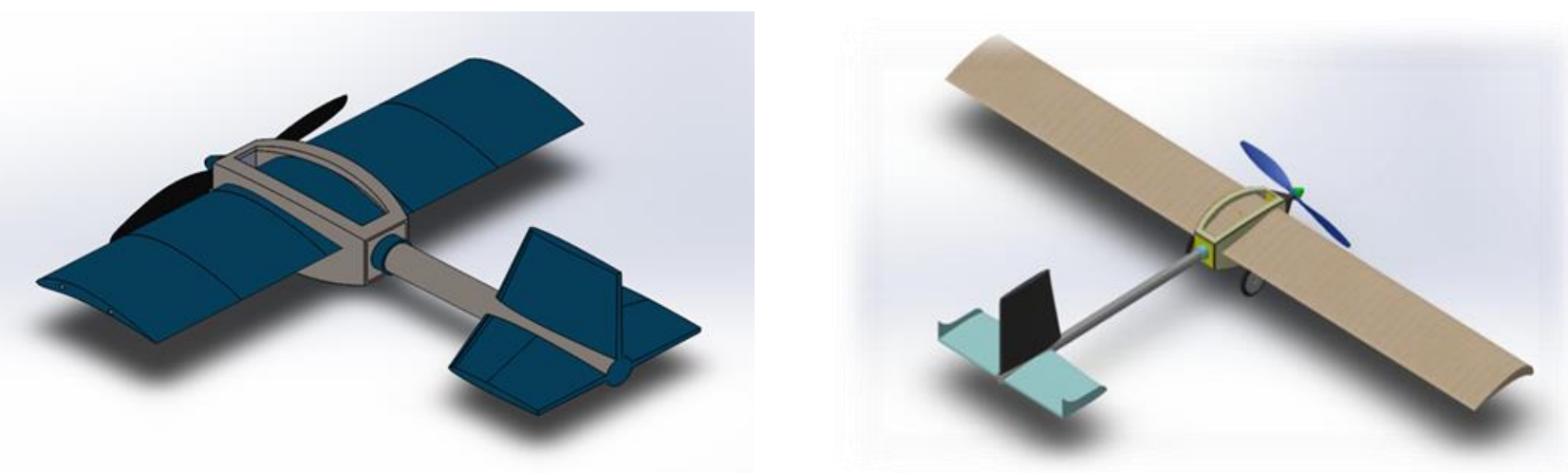

Figure 5 CAD models of alternative designs 

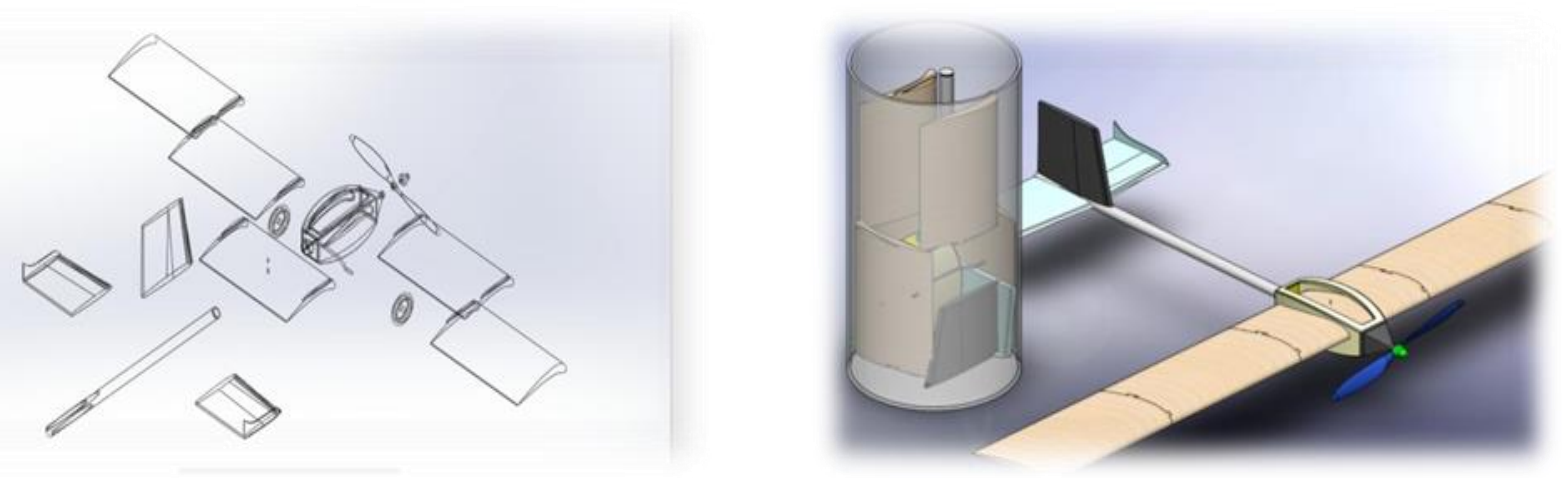

Figure 6 Exploded view of aircraft parts and fitting of parts into cylindrical aircraft container of $15 \mathrm{~cm}$ diameter

Finally, a trial of fitting aircraft parts into cylindrical aircraft container of $15 \mathrm{~cm}$ diameter was simulated in CAD to see if all parts can fit into this box as a competition rule (see Figure 6). After completing 3D models and simulations, 2D drawings for the description of the aircraft designs were prepared (Figure 7).
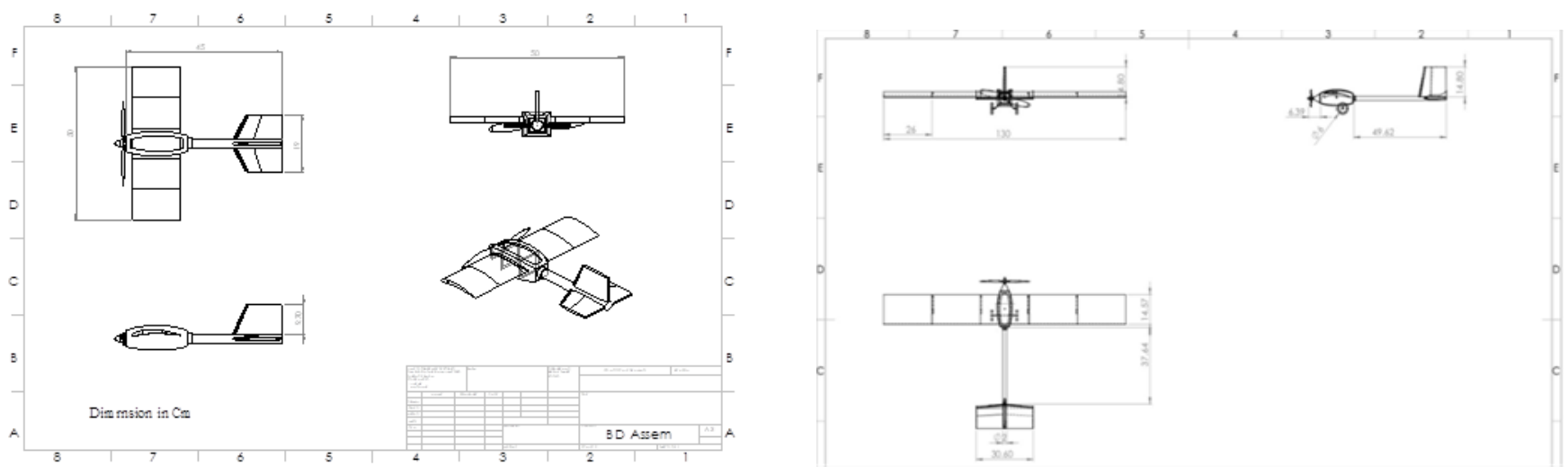

Figure 7 2D Drawings of aircraft designs

\section{Conclusion}

As a conclusion, a design competition is a good chance for the undergraduate engineering students to get an experience into the multidisciplinary design and manufacturing aspects of products since it requires similar efforts as in real life design environment. It helps students to develop different skills such as theoretical knowledge, competitor study, concept development and conceptual design, size and weight calculations, 2D sketching, 3D modeling etc. This project followed the typical steps of the engineering design process, satisfying customer requirements (competition rules) and achieving a good quality design in a given amount of time and proper planning. Students had a chance to practice all the knowledge they have acquired during their undergraduate years of study. As a future work, prototype manufacturing and flight testing of the aircraft is planned after Covid-19 pandemic.

\section{Compliance with ethical standards}

\section{Acknowledgments}

The authors are grateful to the American University of the Middle East for the support in this research.

\section{Disclosure of conflict of interest}

The authors declare no conflict of interest. 


\section{References}

[1] SAE. SAE Collegiate Design Series: Aero Design: About Aero Design. Student Central. Web. 05 Sep 2020.

[2] Raymer DP. Aircraft Design: A Conceptual Approach 4th Edition. Virginia: AIAA. 2006.

[3] Dinc A. Sizing of a Turboprop Unmanned Air Vehicle and its Propulsion System. Journal of Thermal Science and Technology. 2015; 35(2): 53-62.

[4] Dinc A. Preliminary Sizing and Performance Calculations of Unmanned Air Vehicles. In T. Shmelova, Y. Sikirda, N. Rizun, D. Kucherov, \& K. Dergachov (Eds.), Automated Systems in the Aviation and Aerospace Industries. Hershey, PA: IGI Global. 2019; 242-272. doi:10.4018/978-1-5225-7709-6.ch009

[5] Dinc A. Sizing of a Turboprop Engine Powered High Altitude Unmanned Aerial Vehicle and It`s Propulsion System for an Assumed Mission Profile in Turkey. International Journal of Aviation Science and Technology, vm01 (is01). 2020; 5-8. doi:10.23890/IJAST.vm01is01.0101

[6] Dinc, A., \& Elbadawy, I. Global warming potential optimization of a turbofan powered unmanned aerial vehicle during surveillance mission. Transportation Research Part D: Transport and Environment, 85, 102472. 2020; doi:10.1016/j.trd.2020.102472

[7] Dinc, A. NOx emissions of turbofan powered unmanned aerial vehicle for complete flight cycle. Chinese Journal of Aeronautics, 33(6), 1683-1691. 2020; doi:10.1016/j.cja.2019.12.029

[8] Dinc, A., Gharbia, Y. Improving Flight Endurance of a UAV by Employing Porous Wing Tip. American Journal of Engineering Research, vol. 7, no. 11, pp.177-181.2020

[9] Dinc, A. Optimization of turboprop ESFC and NOx emissions for UAV sizing. Aircraft Engineering and Aerospace Technology, 89(3). 2017; doi: 10.1108/AEAT-12-2015-0248

[10] Dinc, A. Military turbofan engine development project cost estimation and technology readiness level based risk factors in a sustainable acquisition management system example. Journal of Sustainable Aviation Researches, 1(1), pp.12-18. 2016; doi: 10.23890/SUHAD.2016.0104

[11] Dinc, A. Optimization of a Turboprop UAV for Maximum Loiter and Specific Power Using Genetic Algorithm. International Journal of Turbo \& Jet-Engines, 33(3), pp. 265-273. 2015; doi:10.1515/tjj-2015-0030

[12] Andrews S, Grossman PB, Hendricks SM, Hong G, McKenzie C, Morette K. Design of a Micro-Class Aircraft for the SAE AeroEast Heavy Lift Competition. Worcester Polytechnic Institute. 2012.

[13] Capozzi R, Chretien E, Clanton S, Daci E, Jones T, Libby A, Peccerillo S, Rice B, Russell J, Sajjadi K, Smith C, Tokatli N. Remote Control Aircraft for the SAE Aero Design West Competition. Worcester Polytechnic Institute. 2018.

[14] Waller B, Chandpen D, Travaglini J, Maberry M, Cushman T, Veilleux Z. Design, Construction and Testing Of A Remote Operation Heavy-Lift Model Aircraft. University of Maine. 2013. 